Research Article

\title{
Financial Performance Management System and Wireless Sharing Network Optimization of Listed Enterprises under BPNN
}

\author{
Shanwei Lin \\ College of Economice Management, Hanshan Normal University, Chaozhou, Guangdong, China \\ Correspondence should be addressed to Shanwei Lin; linshanwei@hstc.edu.cn
}

Received 8 October 2021; Accepted 8 November 2021; Published 9 December 2021

Academic Editor: Sang-Bing Tsai

Copyright ( 92021 Shanwei Lin. This is an open access article distributed under the Creative Commons Attribution License, which permits unrestricted use, distribution, and reproduction in any medium, provided the original work is properly cited.

\begin{abstract}
The study aims to respond to the difficulties in establishing an index system in financial performance management and ensuring the security of wireless sharing network and the local extremum and slow convergence speed of the traditional BP neural network (BPNN). First, Levenberg-Marquardt (LM) is used to optimize BPNN, and an improved BPNN is proposed. Second, the financial performance evaluation system of listed companies based on BPNN is constructed. Finally, a wireless network infusion detection system based on the improved BPNN is proposed and tested by constructing datasets and a real test environment. The results show that (1) the financial performance evaluation system of listed enterprises constructed can evaluate the financial performance of listed enterprises with fewer errors. It is easy to operate, and it has high accuracy and the abilities of self-learning and selfadaptation; (2) Wireless Infusion Detection System (WIDS) based on the improved BP algorithm has a high detection rate and a low error rate. The study provides important technical support for listed enterprises to improve the financial performance management level and market competitiveness and strengthen the security protection of networks.
\end{abstract}

\section{Introduction}

Nowadays, computer and Internet technology penetrates all aspects of people's life and work. In line with the development trend of the Internet, enterprise management gradually enters internationalization [1]. In the process of enterprise development, financial performance management plays a vital role in the long-term development of enterprises. Through the financial activities in the enterprise evaluation system, the operation and management of listed enterprises can be comprehensively and objectively measured, the problems existing in the management are found, and timely corrections are made, laying a good foundation for the sustainable development of enterprises [2-4]. Balanced scorecard, Economic Value Added (EVA), and other methods are widely used for evaluating the financial performance management of listed companies. However, the evaluation effects are not as good as expected because of some defects, such as the difficulty in establishing the index system, the difficulty in determining the relationship between indexes, and the difficulty in allocating the weight of indexes, which are the obstacles to realize modern enterprises $[5,6]$.

BPNN attracts the attention of researchers in various fields in recent years. It has the characteristics of selflearning, self-adaptation, and self-organization and has broad application prospects [7]. Gao implemented a combined performance evaluation model based on BPNN and rough set. The rough set attribute reduction theory is used to filter and optimize the evaluation index, and the key performance index set is obtained. Then, BPNN is used to predict and evaluate the key indexes. The experimental results show that the model greatly reduces the times of training and shortens the learning time [8]. Xu et al. proposed a combination forecasting method for energy consumption of the energy management system (EMS) based on BPNN. The energy consumption of EMS is predicted and analyzed by the grey combination model, grey Markov chain, and BPNN prediction model. The results show that the average relative error of this method is much lower than that of the existing methods, and the prediction accuracy is improved [9]. However, BPNN is easy to fall into local 
minimum and has slow convergence speed. In this case, BPNN is usually combined with other index screening techniques to speed up the convergence of the model and reduce the error when predicting and evaluating the relevant indexes of the enterprise. If BPNN is improved on this basis, its performance will be better. In the increasingly fierce market competition, if enterprises want to stand out and achieve the strategic goal of sustainable development, it is necessary to optimize the management of enterprises and prevent financial crisis or even bankruptcy through the improvement of financial performance evaluation and prediction methods $[10,11]$.

In recent years, the wireless sharing network occupies an important position in the national household and various enterprises, and it brings convenience to people's life and work [12]. The wireless shared network has the characteristics of the simultaneous connection of multiple devices, strong mobility, simple installation, and low cost. It is composed of routers, computers, and other network nodes and realizes the wireless transmission of data [13]. However, the traditional Wireless Infusion Detection System (WIDS) is dependent on the rule base and export base and has weak environmental adaptability, which is not suitable for modern wireless sharing networks and cannot guarantee their security [14].

Based on the above, Levenberg-Marquardt (LM) is used to optimize BPNN and an improved BPNN is proposed. Then, the financial performance evaluation system of listed companies based on BPNN is constructed. Finally, a wireless network infusion detection system based on the improved BPNN is proposed and tested by constructing datasets and a real test environment. The study aims to provide important technical support for listed enterprises to improve their financial performance management levels and market core competitiveness and strengthen system network security protection.

\section{Methods}

\subsection{The Improvement of BPNN}

2.1.1. Brief Introduction to BPNN. BPNN, known as the BP model, is a typical representative of the artificial neural network (ANN) and a most widely used ANN [15]. BPNN is generated by simulating the structure of the human neural network, which is a complex network composed of a large number of connected nodes [16]. BPNN has a multilayer perceptron structure, which mainly includes the input layer, the hidden layer, and the output layer [17]. The structure of the three-layer BPNN is shown in Figure 1.

The input layer and the output layer are mainly to store and transmit external information. All networks contain an input layer and an output layer, but the number of hidden layers of the networks is different [18]. The hidden layer does not directly connect to the outside [19], but its change affects the relationship of the input layer and the output layer. The BP algorithm includes signal forward and reverses propagation in the learning process. The forward propagation is carried out from the input layer to the output layer. If there are many differences between the actual output signal and the expected output signal, it needs to be propagated backward. Backpropagation outputs errors through the hidden layer to the direction of the input layer by layer and distributes them to all units based on the error signal obtained by each layer to adjust the weight of each unit while adjusting the connection strength and threshold of the input layer, the output layer, and the hidden layer so that the error can be gradient descent. This process is repeated until the error is reduced in the allowable range or reaches the preset frequency [20].

2.1.2. The BP Algorithm. The BPNN algorithm is short for the $\mathrm{BP}$ algorithm, and its calculation is performed as follows:

(1) Appropriate input data and target data are selected as sample data to train BPNN

(2) The BPNN model i established and network parameters are initialized.

(3) The computer program is automatically completed and continuously circulated until the preset value is reached through the constructed network training sample data.

(4) Network training is completed, the weights and thresholds are determined, and the results are output [21]. The specific steps are shown in Figure 2.

In short, the BP algorithm can transform the input and signals into nonlinear optimization. Combined with the gradient descent method, the iterative algorithm is used to solve the weight, and the added hidden layer nodes are used to increase the adjustable parameters of the optimization problem, obtaining the optimal solution [22].

The BP algorithm is a nonlinear optimization BPNN mainly used in the following:

(1) Function approximation: let a network approximate a function by training input vectors and output vectors

(2) Pattern recognition: it is linked to the input vector with an undetermined output vector

(3) Classification: the appropriate behavior is classified by the input vector

(4) Data compression: the dimension of the output vector is reduced for transmission or storage

The architecture of networks only includes an input layer, an output layer, and a hidden layer to improve the accuracy, reduce the error, and avoid "overfitting" [23], and the number of nodes in the input layer and the output layer is decided. Therefore, only the number of nodes in the hidden layer is determined. The equation for determining the number of the nodes in the hidden layer is as follows:

$$
y=\sqrt{a+b}+c
$$

where $y$ is the number of the nodes in the hidden layer, $a$ is the number of the nodes in the input layer, $b$ is the number of the nodes in the output layer, and $c$ is a constant from 1 to 10 . 


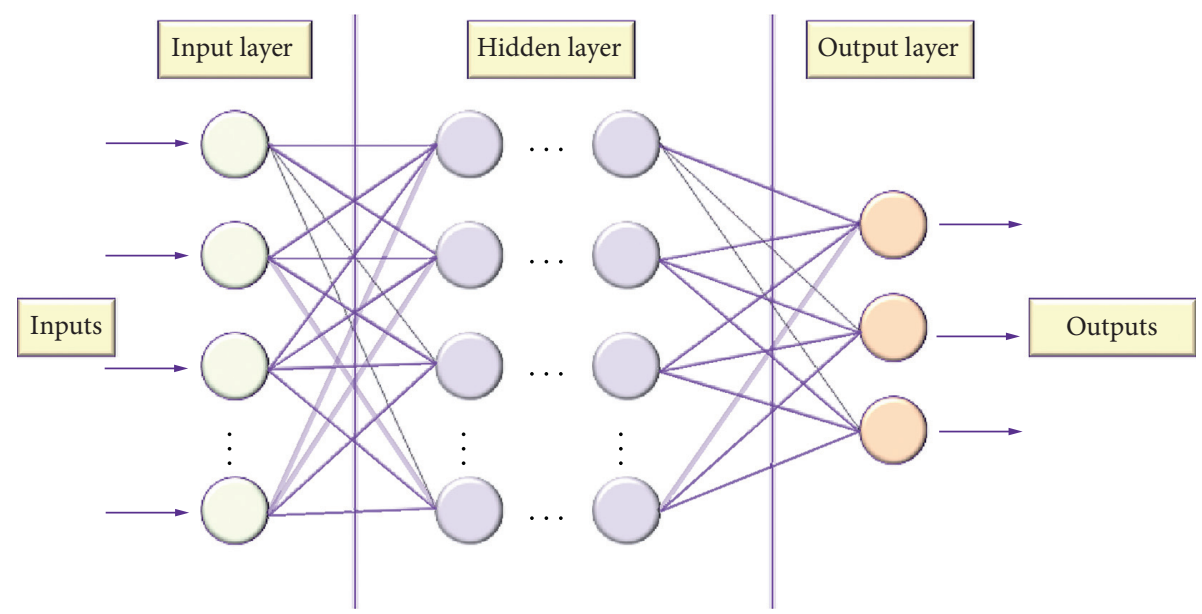

FIGURE 1: Structure of the three-layer BPNN.

2.1.3. LM Optimization Algorithm. Since the traditional BPNN is vulnerable to local extremum and has slow convergence speed, LM is used to optimize BPNN. It is the combination of the Gauss-Newton method and gradient descent method, which obtains the function extremum through iteration and combines the local convergence of the former and the global characteristics of the latter. The calculation equation of LM is expressed as follows.

$x_{k}$ and $x_{k+1}$ are two points in function $f(x)$, and their relationship can be expressed as

$$
x_{k+1}=x_{k}+\Delta x \text {. }
$$

Newton's law is

$$
\Delta x=-\left[\nabla^{2} E(x)\right]^{-1} \nabla E(x)
$$

where $E(x)$ is the error index function, $\nabla^{2} E(x)$ is the Hessian matrix of $E(x), \nabla E(x)$ is the gradient, and $E(x)$ can be expressed as

$$
E(x)=\frac{1}{2} e^{2}(x)
$$

where $e(x)$ is the error; then,

$$
\begin{aligned}
\nabla E(x) & =J^{T}(x) e(x), \\
\nabla^{2} E(x) & =J^{T}(x) e(x)+S(x), \\
S(x) & =\sum e_{i}(x) \nabla^{2} e_{i}(x) .
\end{aligned}
$$

In the above equations, $S(x)$ is the Jacobian $(J)$ matrix and $J$ is expressed as

$$
J(x)=\left[\begin{array}{cccc}
\frac{\partial e_{1(x)}}{\partial x_{1}} & \frac{\partial e_{1(x)}}{\partial x_{2}} & \cdots & \frac{\partial e_{1(x)}}{\partial x_{n}} \\
\vdots & \ddots & \cdots & \vdots \\
\frac{\partial e_{n(x)}}{\partial x_{1}} & \frac{\partial e_{n(x)}}{\partial x_{2}} & \cdots & \frac{\partial e_{n(x)}}{\partial x_{n}}
\end{array}\right]
$$

The calculation rule of the Gauss-Newton method is as follows:

$$
\Delta x=\left[J^{T}(x) J(x)\right]^{-1} J(x) e(x) .
$$

The improved Gauss-Newton method is called the LM algorithm, which is expressed as

$$
\Delta x=\left[J^{T}(x) J(x)+\mu I\right]^{-1} J(x) e(x) .
$$

where $\mu$ is the proportional coefficient, which is a constant greater than 0 , and it is the unit matrix.

\subsection{Establishment of the Performance Evaluation Index System (PEIS) of Listed Enterprises under BPNN}

2.2.1. Index Selection of the Financial Performance Evaluation System Based on BPNN and Its Construction Principles

(1) Clarity Principle. The selected indexes should be simple and clear, and their meanings should have no ambiguity.

(2) Feasibility Principle. The selected indexes should be feasible, and too fine indexes will lead to cumbersome. The cost of the data acquisition of relevant indexes should also be considered. If the cost of data acquisition is higher than the returns it can bring, the indexes should be deleted or replaced.

(3) Adaptability Principle. Different listed enterprises have their unique business and development models, and a set of financial performance evaluation index systems cannot be applied to all enterprises. Therefore, the evaluation indexes should be based on fully understanding the research object and comply with the characteristics of the enterprise.

(4) Predictive Principle. The financial performance evaluation system not only evaluates the past performance but also makes a reasonable prediction and guidance for the future development of enterprises through a comprehensive evaluation system. 


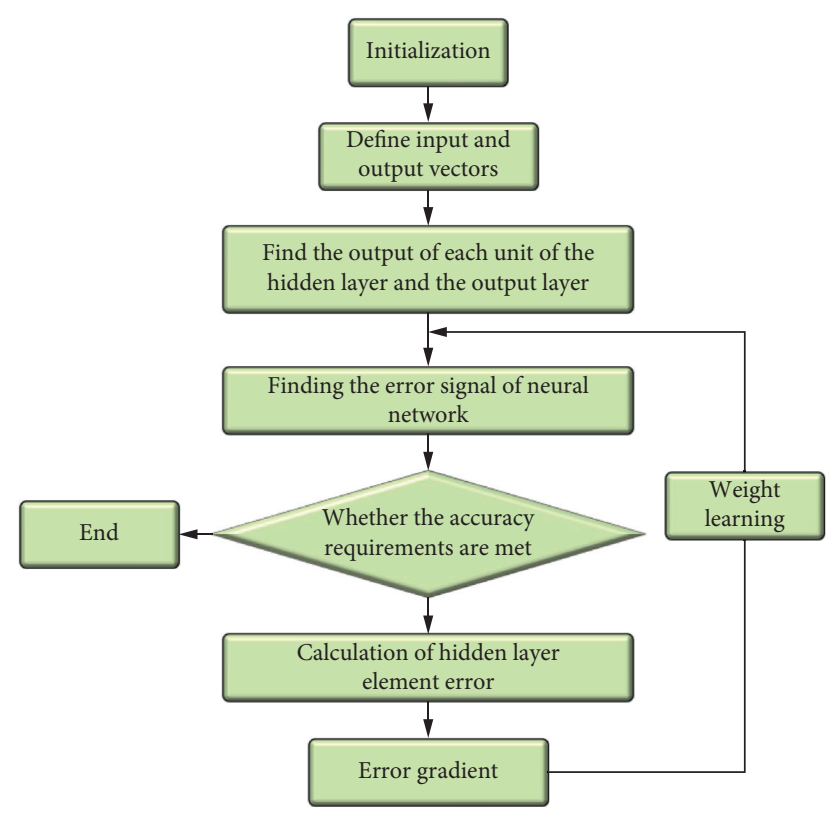

FIGURE 2: Flowchart of the BP algorithm.

(5) Consistency Principle. The established enterprise financial performance evaluation system should be helpful to realizing the strategic objectives of enterprises, reflecting their characteristics, and allocating resources reasonably [2].

2.2.2. Construction of Performance Evaluation Index System (PEIS) of Listed Enterprises Based on BPNN. Profitability, operational capacity, solvency, development capacity, cash flow capacity, and risk resistance are often used as important indexes to comprehensively show business management capabilities and achievements [24]. Since all enterprises are set up to make profits, the most important index to explore the management level of an enterprise is the profitability of the above six indexes. Therefore, PEIS of listed companies is established with profitability as the first-grade index, net asset return, cost rate of the main business, price-to-earnings ratio, asset-to-liability ratio, inventory turnover rate, and income growth rate of the main business as the second-grade indexes. Among them, the net asset return, inventory turnover rate, and income growth rate of the main business are classified as positive indexes, the cost rate of the main business as the negative index, and the asset-to-liability ratio and price-to-earnings ratio as interval indexes. The indexes and their calculation equations are shown in Table 1.

\subsubsection{Construction of PES of Listed Enterprises Based on $B P N N$}

(1) Dimensionless Processing of Sample Financial Indexes. The financial performance evaluation indexes of listed enterprises provided above are used to collect sample data from "CSMAR financial series research database-China listed enterprise financial index analysis database." Different financial performance indexes have different dimensions and units, so they need to be normalized. Here, the range transformation method is used for dimensionless processing [25]. The processing rules are as follows: first, equation (9) is used for calculating the large index, known as the large variables. Second, equation (10) is used for calculating the small index, known as the minimal variables. Third, the variable whose index is optimal within a certain range is called an interval variable, and equations (11)-(13) are used to calculate them.

$$
\begin{aligned}
Y_{i j} & =\frac{\max \left(x_{i 1}, x_{i 2}, \ldots, x_{i n}\right)-x_{i j}}{\max \left(x_{i 1}, x_{i 2}, \ldots, x_{i n}\right)-\min \left(x_{i 1}, x_{i 2}, \ldots, x_{i n}\right)}, \\
Y_{i j} & =\frac{x_{i j}-\min \left(x_{i 1}, x_{i 2}, \ldots, x_{i n}\right)}{\max \left(x_{i 1}, x_{i 2}, \ldots, x_{i n}\right)-\min \left(x_{i 1}, x_{i 2}, \ldots, x_{i n}\right)}, \\
Y_{i j} & =\frac{\max \left(x_{i 1}, x_{i 2}, \ldots, x_{i n}\right)-x_{i j}}{\max \left(x_{i 1}, x_{i 2}, \ldots, x_{i n}\right)-\bar{x}} x_{i j}<\bar{x}, \\
x_{i j} & =\bar{x}, \\
Y_{i j} & =\frac{x_{i j}-\min \left(x_{i 1}, x_{i 2}, \ldots, x_{i n}\right)}{\max \left(x_{i 1}, x_{i 2}, \ldots, x_{i n}\right)-\min \left(x_{i 1}, x_{i 2}, \ldots, x_{i n}\right)} x_{i j} .
\end{aligned}
$$

In equations (11)-(13), $x_{i j}$ is the value of the $i$-th index in the $j$ enterprise. $Y_{i j}$ is the value after processing.

(2) Determining the Nodes of BPNN. Six financial performance evaluation indexes are determined above. Therefore, the number of the nodes in the input layer of BPNN is six, and the number of the nodes in the output layer is one. According to the equation, the number of nodes in the hidden layer is four. When the financial performance of listed enterprises is evaluated, the evaluation data can be obtained by inputting the corresponding index data.

\subsection{Construction of WIDS Based on the Improved BP Algorithm}

2.3.1. Principles of the WID Algorithm. The essence of WID is to identify the behavior that attempts to invade to the network. WID mainly includes data acquisition, feature extraction, data analysis, and response mechanism. It is used to obtain data including network packets, host logs, and applications. Due to the great number and disorder of data, WIDS also needs to extract the features of the key data and make them in a certain order. Then, some detection techniques are used to analyze the features and judge whether there are security vulnerabilities in the network. WID can analyze the data inside or outside the network in real time, identify infusion attempts, and alert the system administrator and prevent infusion in time before the network system is damaged [26]. The basic working principle of WIDS is shown in Figure 3. 
TABLE 1: PEIS of listed enterprises.

\begin{tabular}{lcc}
\hline $\begin{array}{l}\text { First-grade } \\
\text { indexes }\end{array}$ & Second-grade indexes & Calculation equations \\
\hline $\begin{array}{c}\text { Profitability } \\
\text { Net asset return }\end{array}$ & $\begin{array}{c}\text { Net profit/net assets } \\
\text { Cost rate of the main business } \\
\text { Price-to-earnings ratio } \\
\text { Asset-to-liability ratio } \\
\text { Inventory turnover rate } \\
\text { The income growth rate of the } \\
\text { main business }\end{array}$ & $\begin{array}{c}\text { Cost } / \text { net income of the main business } \\
\text { Thice per share/earnings per share per year } \\
\text { Total liabilities/total assets } \times 100 \%\end{array}$ \\
& $\begin{array}{c}\text { (Current income of the main business }- \text { the last income of the main business }) / \text { the last } \\
\text { income of the main business } \times 100 \%\end{array}$ \\
\hline
\end{tabular}

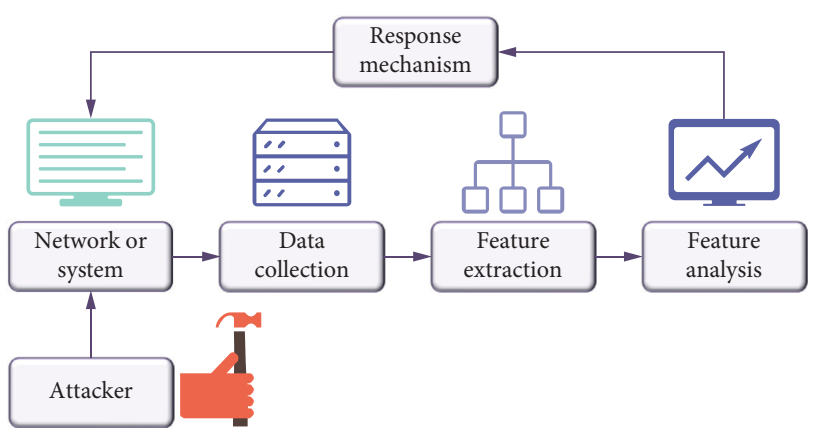

FIgURE 3: Working principle of WIDS.

2.3.2. Simulation of a Real Environment. A real environment based on wireless networks is constructed to test the proposed method. In the experiment, the proposed method is attacked by using test scripts. A representative attack example is made to illustrate the overall process of the experiment, and the detection model designed based on wireless networks is used for attack detection. The specific process is as follows:

(1) Environment: a wireless access point with a legitimate user list.

(2) Tool: a terminal with wireless card interfaces, also known as the OmniPeek packet capture tool.

(3) Method: the attacker first uses OmniPeek to capture the data from the wireless network card interface and obtains the MAC address. Then, he connects the MAC address of the attack device to that of the legitimate user, and the attack is successful.

In the test process, the times of abnormal disorder are used to determine whether the intrusion behavior exists. In general, the abnormal disorder is greater than 3 . The rules of determining the times of abnormal disorder are as follows:

$$
\left|x_{1}-x_{2}\right|>\theta
$$

where $x_{1}$ is the serial number of the previous message, $x_{2}$ is the serial number of the current message $s$, and $\theta$ is the rule threshold.

\subsection{Experimental Methods}

2.4.1. Validation of the Effectiveness of the Financial Performance Evaluation System of Listed Companies
(1) Establishment of the Datasets. The enterprise-related data used are all from the Wind Economic Database, which integrates a large number of global macro and industry statistics. The data in the database can be searched and analyzed fast, and the database has powerful graphics functions and can extract the dynamic features of data in Excel. It is an important database for economists, strategic analysts, and industry researchers. The financial data of 20 real estate enterprises listed on the Shenzhen and Shanghai stock exchanges from 2020 to 2021 are selected as the sample set after dimensionless processing. The securities codes are symbolized with letters and abbreviations to make the process simple and clear. Some of the sample data after dimensionless processing is shown in Table 2.

(2) Parameter Setting. The adaptive learning algorithm Traingdx with momentum is selected as the training function, and the model based on BPNN is trained in a Matlab development environment. In the above 20 samples, the first 15 are selected as training samples to determine the weights and thresholds. The expected output value of the sample is obtained by the export evaluation method. The last five sample data are used as test sets to verify the validity of the model. In actual operation, the maximum times of training are set as 10000, the convergence accuracy as $10^{-3}$, and the others as default values. The index data are input into BPNN to start training.

2.4.2. Simulation of WID Based on the Traditional BP Algorithm and the Improved BP Algorithm. (1) Establishment of the Datasets. Knowledge Discovery and Data Mining Cup (KDD) provided by the Lincoln Laboratory of Massachusetts Institute of Technology are used to test the performance of the infusion detection system based on wireless networks. Various types of users and different network traffic and attack methods are simulated on the KDD Cup, which is a dataset dedicated to network infusion detection. Three kinds of infusion attacks including Smurf, Back, and Nmap, and normal data from the KDD CUP 99 dataset are used to construct the dataset to train the model. The test set is also randomly selected from the dataset. 1000 samples of each attack are extracted from all test samples and mixed with 1000 normal samples for model validation. Under the same conditions, the model based on the standard BPNN before improvement is compared with the improved BPNN.

(2) Model Parameter Setting and Evaluation Index. The maximum training times of the model based on the improved BP are set as 10000, the convergence error as 0.05 , 
TABLE 2: Sample data of 20 real estate enterprises after dimensionless processing.

\begin{tabular}{|c|c|c|c|c|c|c|}
\hline $\begin{array}{l}\text { Securities } \\
\text { codes }\end{array}$ & $\begin{array}{c}\text { Return on } \\
\text { equity }\end{array}$ & $\begin{array}{c}\text { Main business cost } \\
\text { ratio }\end{array}$ & $\begin{array}{l}\text { Price-to-earnings } \\
\text { ratio }\end{array}$ & $\begin{array}{c}\text { Asset-to-liability } \\
\text { ratio }\end{array}$ & $\begin{array}{c}\text { Inventory } \\
\text { turnover }\end{array}$ & $\begin{array}{c}\text { Main business income } \\
\text { growth rate }\end{array}$ \\
\hline $\mathrm{A}$ & 0.0798 & 0.0826 & 0.3725 & 0.2796 & 0.7201 & 0.2861 \\
\hline B & 0.0315 & 0.3005 & 0 & 0.7951 & 0.1997 & 0.0618 \\
\hline $\mathrm{C}$ & 0.1599 & 0.2156 & 0.9524 & 0.3015 & 0.3545 & 0.0744 \\
\hline $\mathrm{D}$ & 0.0702 & 0.6203 & 0.7495 & 0.9418 & 0.2807 & 0.0488 \\
\hline $\mathrm{E}$ & 0.2011 & 0.2812 & 0.9795 & 1 & 1 & 0.0296 \\
\hline $\mathrm{F}$ & 0.1256 & 0 & 0.8456 & 0.6219 & 0.2958 & 0.0677 \\
\hline G & 0.2219 & 0.7986 & 1 & 0.8408 & 0.0309 & 0.0194 \\
\hline$\cdots$ & $\cdots$ & $\cdots$ & $\cdots$ & $\cdots$ & $\cdots$ & $\cdots$ \\
\hline $\mathrm{O}$ & 0.2413 & 0.8957 & 0.9791 & 1 & 0.0905 & 0 \\
\hline $\mathrm{P}$ & 0.1802 & 0.2961 & 0.9854 & 0 & 0.4085 & 1 \\
\hline Q & 0.2605 & 0.2488 & 0.9886 & 0.9308 & 0.8412 & 0.0608 \\
\hline $\mathrm{R}$ & 0.9112 & 1 & 0.9524 & 0.7009 & 0.5103 & 0.1662 \\
\hline$S$ & 0.3418 & 0.6709 & 0.9862 & 0.6608 & 0.0101 & 0.0715 \\
\hline $\mathrm{T}$ & 0.9076 & 0.3711 & 0.9837 & 0.8795 & 0.5398 & 0.0158 \\
\hline
\end{tabular}

and the others as the default values. The evaluation is conducted by calculating the error positive rate (FPR), detection rate (DR), and underreporting rate (UR), and the calculation equations are as follows:

$$
\begin{aligned}
F P R & =\frac{A}{X}, \\
D R & =\frac{B}{X}, \\
U R & =1-\frac{B}{X} .
\end{aligned}
$$

where $X$ is the normal number of samples, $A$ is the number of normal samples misreported as infusion, and $B$ is the number of infusion samples detected.

\section{Results}

\subsection{Empirical Analysis Results of the Financial PEIS of Listed Enterprises}

3.1.1. Training Results of the Model Based on BPNN. Linear regression analysis and training results of the model based on BPNN are shown in Figures 4 and 5 .

Figure 4 shows the linear regression analysis of the actual output and simulation output of BPNN and the correlation between the output value and the actual value. The closer the correlation coefficient R2 is to 1, the higher the fitting degree of the two is, and the more accurate the output is. The correlation coefficient between the output value of the model based on BPNN and the actual value is as high as 0.99945, indicating that BPNN has high accuracy for enterprise financial performance evaluation and can meet the actual needs. From the training results in Figure 5, it is found that the model based on BPNN reaches the expected convergence after 2968 times of training. The fitting degree is high, and the network performance can meet the actual requirements. The trained specific gravity threshold is used to simulate the data through BPNN. The comparison between the actual output and the expected is shown in Figure 6.
Figure 6 shows that the actual results of the sample data through the network are highly similar to the expected values, and the error is also controlled within a limited range. It is proved that the BPNN model designed can reveal the nonlinear relationship between the enterprise financial performance indexes through training and learning.

3.1.2. Simulation Evaluation Results of the Model Based on $B P N N$. The weights and thresholds obtained by training the BPNN model are used to simulate and evaluate the last five samples. The results are shown in Figure 7.

The simulation results of the performance evaluation results of five listed real estate enterprises show that the financial performance level of enterprises with securities code $\mathrm{S}$ is the highest, followed by $\mathrm{R}, \mathrm{Q}$, and $\mathrm{P}$, and the financial performance level of enterprises with securities code $\mathrm{T}$ is the lowest.

\subsection{Test Results of WIDS Based on the Improved BP Algorithm}

3.2.1. Training Results of the WID Model. The comparison of training results between the traditional $\mathrm{BP}$ algorithm and the improved BP algorithm is shown in Figure 8.

In Figure 8, the times of training are used to achieve convergence, and the ordinate expresses the requirement of training accuracy. The figure shows that under the same error value requirement, the improved BP algorithm uses fewer training times than the traditional BP algorithm. When the error requirement is less than 0.1 , the gap between the training times used by the two is increasing. This proves that the performance of the improved BP algorithm is greatly improved compared with the traditional BP algorithm.

3.2.2. Performance Test Results of the Improved BP Algorithm. The improved BP algorithm is constructed, and the traditional algorithm is used to detect the correct rate of various attacks on the training dataset, and the comparison of the detection rate, false alarm rate, and false-negative rate of the algorithm on the test set is shown in Figure 9. 


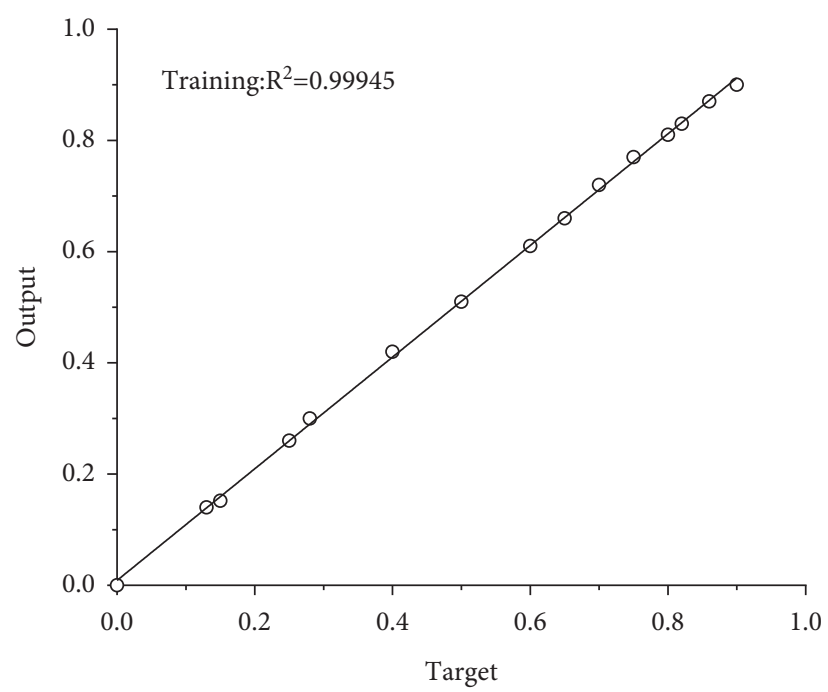

FIgURE 4: Training error curve of BPNN.

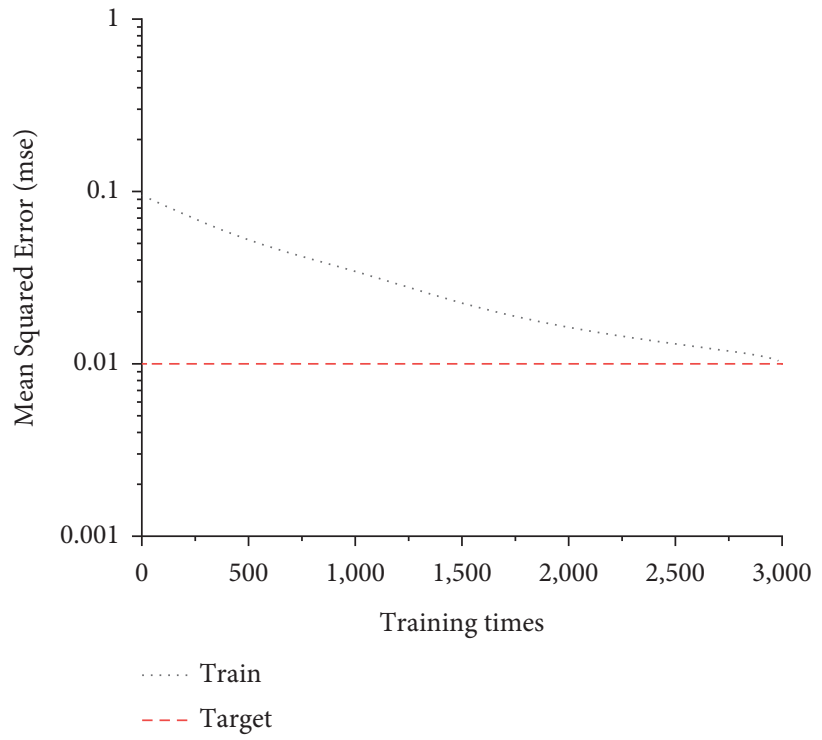

FIgURE 5: Training results of BPNN.

Figure 9 shows that the average detection rate of the traditional BP algorithm for three types of attacks is $79.98 \%$, while the average detection rate of the model implemented is $93.75 \%$, which is higher than that of the traditional algorithm by more than $17.22 \%$. The false alarm rate of the infusion detection of the improved BP algorithm is 3.8\%, which is about $42.1 \%$ lower than $5.4 \%$ of the traditional BP algorithm. The detection rate is $94.39 \%$, which is about $7.1 \%$ higher than $88.16 \%$ of the traditional BP algorithm, and the underreporting rate is $4.42 \%$, which is about $128.7 \%$ lower than $10.11 \%$ of the traditional BP algorithm.

3.2.3. Real Environment of the WID Model. The results of infusion detection in the real environment are shown in Figure 10.
The sample test results show that the detection rates of the WIDS based on the improved BP algorithm for the six types of attacks, namely, the disconnection authentication, connection attack, disconnection, authentication attack, camouflage user, and reconnection attack, are all greater than $99 \%$, with the highest of $99.6 \%$. Also, the error rate is controlled below $1.5 \%$, with a minimum of $0.4 \%$. In summary, the WIDS designed has a high detection rate, a low error rate, and a wide application prospect.

\section{Discussion on Experimental Results}

Two models are implemented, and they are the financial performance evaluation system of listed enterprises based on BPNN and the wireless network infusion detection system based on the improved BP algorithm. First, the financial 


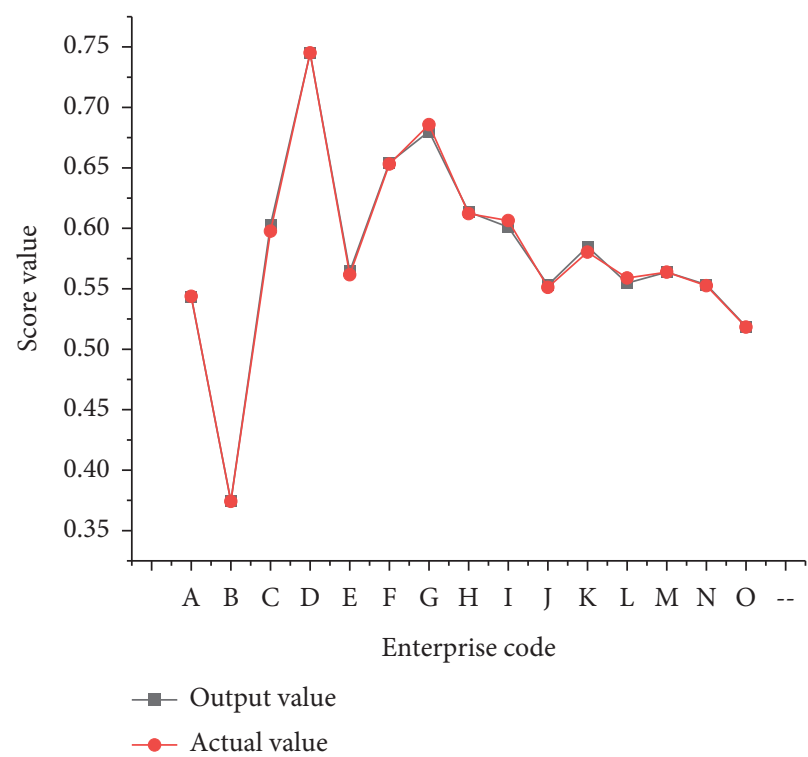

(a)

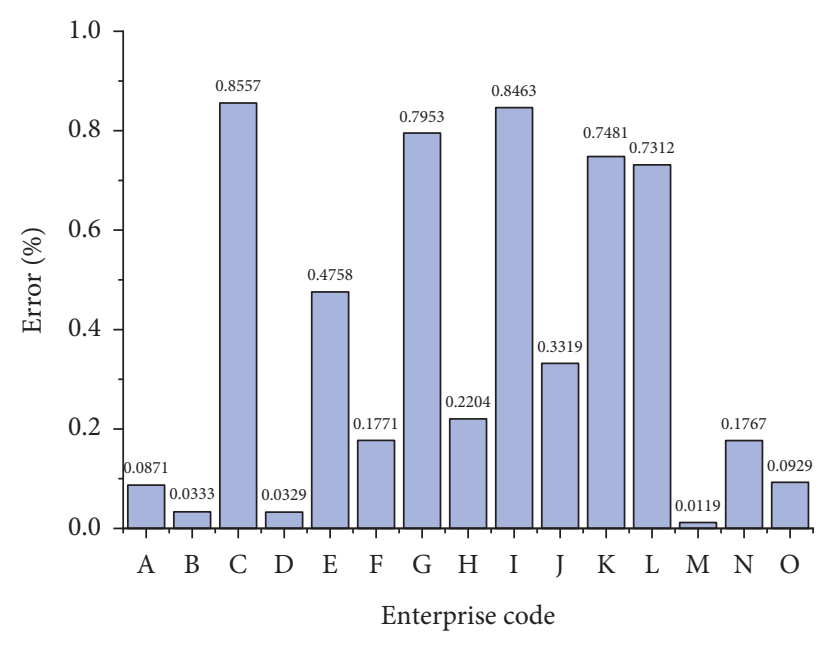

(b)

Figure 6: Comparison of the output value based on BPNN and the actual value. (a) Comparison of the output based on BPNN with the actual value. (b) Errors between the output and the actual value.

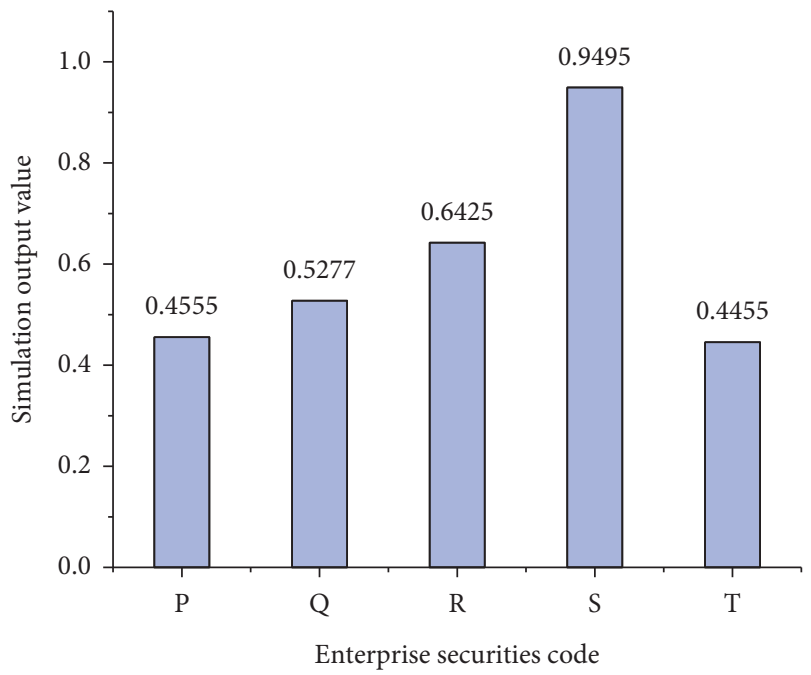

FIGURE 7: Simulation results of the samples based on BPNN.

performance evaluation system is used to evaluate the financial performance of real estate enterprises listed on the Shenzhen and Shanghai stock exchanges. The linear regression analysis of the output value and the actual value of the model is carried out. The results show that the correlation coefficient between the output value and the actual value of the model is as high as 0.99945 . The error between the output value and the actual value can also be controlled within $0.8557 \%$, which indicates that the evaluation results are more accurate. The financial performance evaluation system of listed companies based on BPNN can evaluate the financial performance. Only the corresponding financial performance evaluation indexes are input into the BP model. The financial performance evaluation results can be output. According to the results, the following questions are asked:

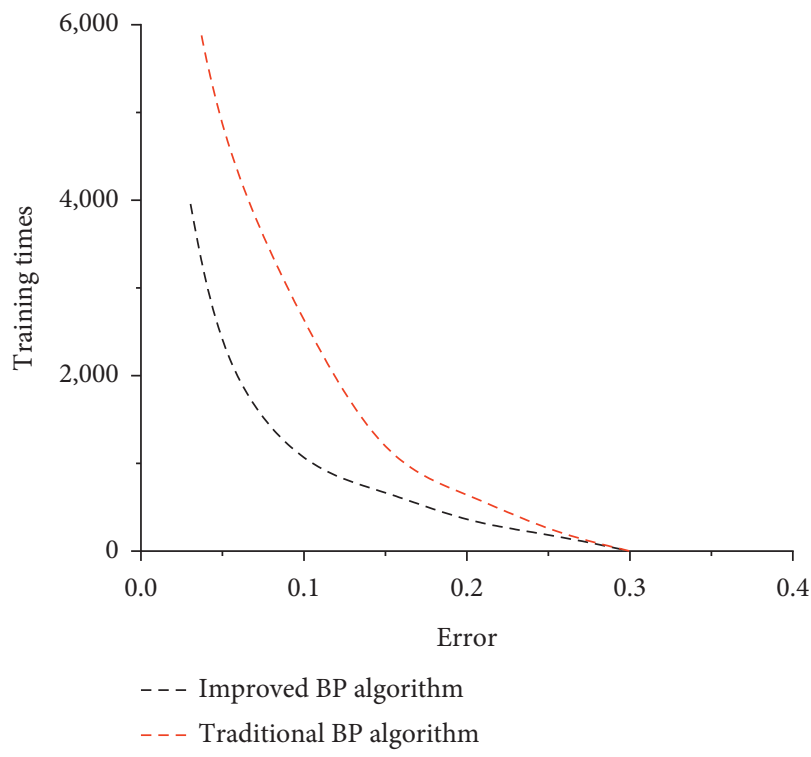

FIGURE 8: Comparison of the training results between the traditional BP algorithm and the improved BP algorithm.

(1) whether the performance level of enterprises in the industry is good; (2) whether it has a competitive advantage compared with other enterprises; and (3) which aspects need to be improved to provide technical support for enterprises to improve their financial performance management level and core competitiveness.

Second, with the standard BP algorithm before optimization as the control, the KDD Cup dataset is used to test the performance of the improved $\mathrm{BP}$ algorithm. The results show that under the same requirements for convergence accuracy, the training times of the improved BP algorithm are less than those of the standard BP algorithm. Moreover, 


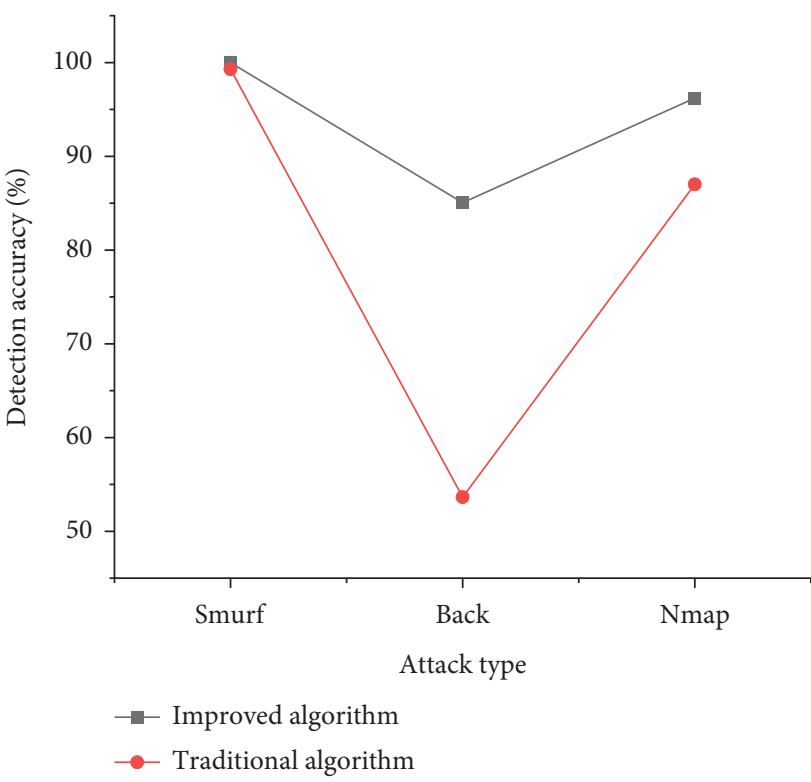

(a)

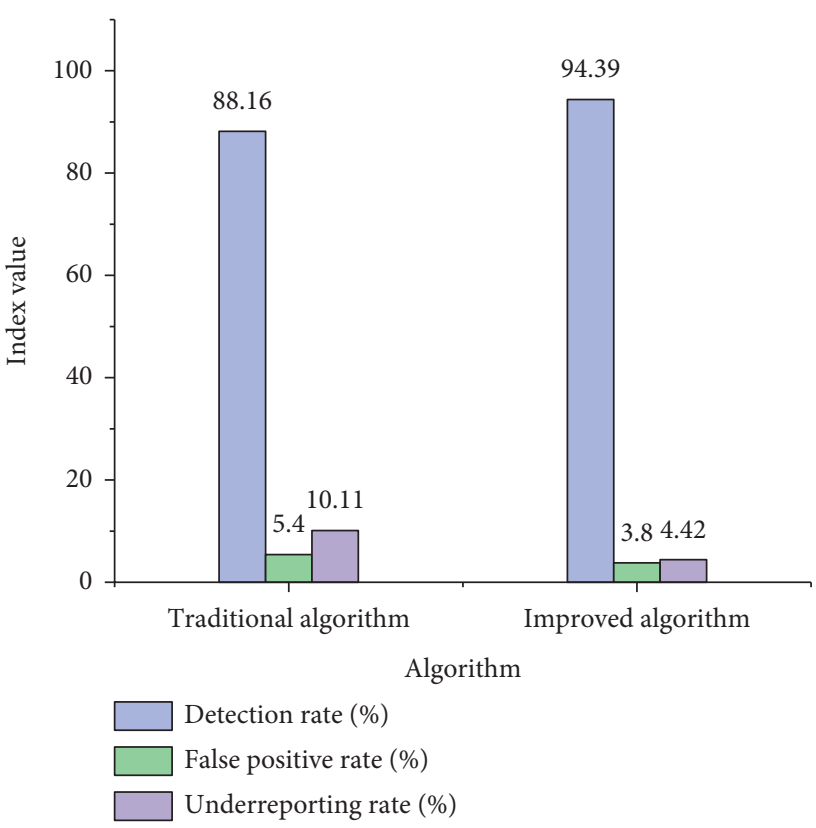

(b)

FiguRE 9: Comparison of detection results of different algorithms for various attacks. (a) Comparison of the detection accuracy of attacks. (b) Comparison of the detection rate, false alarm rate, and false-negative rate.

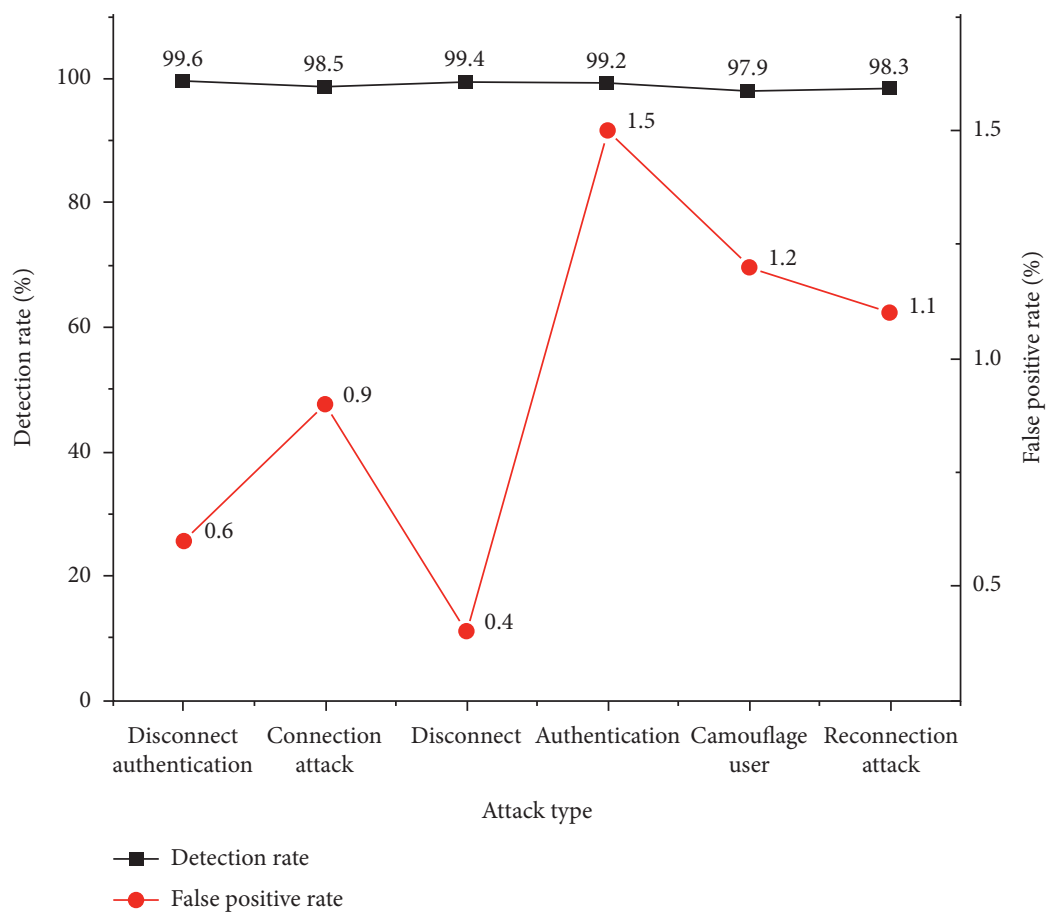

FIgURE 10: Sample test results.

the higher the accuracy requirements are, the greater the gap between the two is, indicating that the training speed of the improved algorithm is faster and the improvement effect is good. The false alarm rate of the improved algorithm in infusion detection is $3.8 \%$, which is about $42.1 \%$ lower than $5.4 \%$ of the traditional $\mathrm{BP}$ algorithm. The detection rate is $94.39 \%$, which is about $7.1 \%$ higher than $88.16 \%$ of the traditional BP algorithm; the underreporting rate is $4.42 \%$, which is about $128.7 \%$ lower than $10.11 \%$ of the traditional $\mathrm{BP}$ algorithm. In summary, the infusion detection of the improved BP algorithm is more accurate than that of the traditional BP algorithm, and its detection accuracy is greatly improved. The wireless network infusion detection model based on the improved BP algorithm is feasible. 


\section{Conclusions}

The financial performance management level directly affects the sustainable development of listed enterprises, but the traditional performance management level cannot meet the practical needs. The wireless sharing network has a special transmission mode and is not applicable to the traditional WIDS. Moreover, the traditional BPNN is vulnerable to the local extremum and has slow convergence speed. First, an improved BP algorithm is proposed by using the LM algorithm to optimize BPNN. Second, based on the improved BP algorithm, the financial performance evaluation system of listed enterprises and the wireless network infusion detection system are constructed. Through the empirical analysis of the performance evaluation system designed and the test of WIDS, the results show that (1) the financial performance evaluation system designed can evaluate the financial performance of listed enterprises with a few errors. It is easy to operate, and it has high accuracy and the abilities of self-learning and self-adaptation; (2) WIDS based on the improved $\mathrm{BP}$ algorithm has a high detection rate and a low error rate. The innovation is that LM is mainly used to optimize BPNN, which greatly accelerates the training speed while ensuring the accuracy of the model. The shortcomings of this study lie in the following: (1) the number of the indexes of the performance evaluation system is few, and it needs to be expanded; (2) WIDS can only capture and warn infusion behaviors, but it cannot intercept them. On this basis, it is necessary to combine the interception system to form a more complete security system. The study provides important technical support for listed companies to improve the financial performance management level and market competitiveness and strengthen the security protection of networks.

\section{Data Availability}

The data used to support the findings of this study are available from the corresponding author upon request.

\section{Conflicts of Interest}

The author declares no conflicts of interest.

\section{References}

[1] S. Zhao and L. Zhang, "Analysis of enterprise management information system based on cloud computing," Journal of Physics: Conference Series, vol. 1533, no. 2, Article ID 022038, 2020.

[2] Y. Deng, S. Zou, and D. You, "Financial performance evaluation of nuclear power-related enterprises from the perspective of sustainability," Environmental Science and Pollution Research, vol. 27, no. 10, pp. 11349-11363, 2020.

[3] P. R. Srivastava, Z. Zuopeng Zhang, and P. Eachempati, "Deep neural network and time series approach for finance systems," Journal of Organizational and End User Computing, vol. 33, no. 5, pp. 204-226, 2021.

[4] P. Wang and W. Han, "Construction of a new financial E-commerce model for small and medium-sized enterprise financing based on multiple linear logistic regression," Journal of Organizational and End User Computing, vol. 33, no. 6, pp. 1-18, 2021.

[5] C. Oliveira, "Balanced scorecard in universities," Journal of Intercultural Management, vol. 10, no. 4, pp. 57-83, 2019.

[6] C. H. Wu, Z. Yan, S. B. Tsai, W. Wang, B. Cao, and X. Li, "An empirical study on sales performance effect and pricing strategy for E-commerce: from the perspective of mobile information," Mobile Information Systems, vol. 2020, Article ID 7561807, 8 pages, 2020.

[7] N. Keegan, S. Y. Ji, A. Chaudhary, C. Concolato, B. Yu, and D. H. Jeong, "A survey of cloud-based network intrusion detection analysis," Human-centric Computing and Information Sciences, vol. 6, no. 1, pp. 1-16, 2016.

[8] J. Gao, "Performance evaluation of manufacturing collaborative logistics based on BP neural network and rough set," Neural Computing \& Applications, vol. 33, no. 2, pp. 739-754, 2021.

[9] S. Xu, R. Alturki, A. U. Rehman, and M. U. Tariq, "BP neural network combination prediction for big data enterprise energy management system," Mobile Networks and Applications, vol. 26, no. 1, pp. 184-190, 2021.

[10] M. S. M. Mustafa and M. Taqi, "A study on the financial performance evaluation of Punjab National Bank," International Journal of Business and Management Invention, vol. 6, no. 1, pp. 5-15, 2017.

[11] S. B. Tsai, "Using DEMATEL-based ANP model to measure the successful factors of E-commerce," Journal of Global Information Management, vol. 26, no. 1, pp. 120-135, 2018.

[12] J. Park, S. Samarakoon, M. Bennis, and M. Debbah, "Wireless network intelligence at the edge," Proceedings of the IEEE, vol. 107, no. 11, pp. 2204-2239, 2019.

[13] P. Park, S. C. Ergen, C. Fischione, C. Lu, and K. H. Johansson, "Wireless network design for control systems: a survey," IEEE Communications Surveys \& Tutorials, vol. 20, no. 2, pp. 978-1013, 2017.

[14] L. Zhang, F. Wang, T. Sun, and B. Xu, "A constrained optimization method based on BP neural network," Neural Computing \& Applications, vol. 29, no. 2, pp. 413-421, 2018.

[15] T. Li, J. Sun, and L. Wang, "An intelligent optimization method of motion management system based on BP neural network," Neural Computing \& Applications, vol. 33, no. 2, pp. 707-722, 2021.

[16] J. Wang, P. Shi, P. Jiang et al., "Application of BP neural network algorithm in traditional hydrological model for flood forecasting," Water, vol. 9, no. 1, p. 48, 2017.

[17] B. Wu, S. Han, J. Xiao, X. Hu, and J. Fan, "Error compensation based on BP neural network for airborne laser ranging," Optik, vol. 127, no. 8, pp. 4083-4088, 2016.

[18] Y. C. Lin, D.-D. Chen, M.-S. Chen, X.-M. Chen, and J. Li, “A precise BP neural network-based online model predictive control strategy for die forging hydraulic press machine," Neural Computing \& Applications, vol. 29, no. 9, pp. 585-596, 2018.

[19] J. Liu, X. Jin, F. Dong, L. He, and H. Liu, "Fading channel modelling using single-hidden layer feedforward neural networks," Multidimensional Systems and Signal Processing, vol. 28, no. 3, pp. 885-903, 2017.

[20] Y. Lv, W. Liu, Z. Wang, and Z. Zhang, "WSN localization technology based on hybrid GA-PSO-BP algorithm for indoor three-dimensional space," Wireless Personal Communications, vol. 114, no. 1, pp. 167-184, 2020.

[21] X. Zhang, P. Yang, C. Tan, and W. Ying, "BP algorithm for the multireceiver SAS," IET Radar, Sonar \& Navigation, vol. 13, no. 5, pp. 830-838, 2019. 
[22] Z. Zhao, Q. Xu, and M. Jia, "Improved shuffled frog leaping algorithm-based BP neural network and its application in bearing early fault diagnosis," Neural Computing \& Applications, vol. 27, no. 2, pp. 375-385, 2016.

[23] Y.-G. Zhang, J. Tang, R.-P. Liao et al., "Application of an enhanced BP neural network model with water cycle algorithm on landslide prediction," Stochastic Environmental Research and Risk Assessment, vol. 35, no. 6, pp. 1273-1291, 2021.

[24] Y. Zhang, "The construction of enterprise financial performance evaluation index system based on computer binary tree theory," Journal of Physics: Conference Series, vol. 1744, no. 4, Article ID 042065, 2021.

[25] V. I. Zalkind, Y. A. Zeigarnik, V. L. Nizovskiy, L. V. Nizovskiy, and S. S. Schigel, "Superheated metastable atomized water plume diagnostics peculiarities in confusor-diffuser nozzles; atomizaton process: dimensionless treatment," Journal of Physics: Conference Series, vol. 1675, no. 1, Article ID 012031, 2020.

[26] Z. Dewa and L. A. Maglaras, "Data mining and intrusion detection systems," International Journal of Advanced Computer Science and Applications, vol. 7, no. 1, pp. 62-71, 2016. 